\title{
On Prospects of Development of Telecommunication Systems and Services based on Virtual Reality Technology
}

\author{
Andrey Zuev, Roman Bolbakov \\ Institute of Information Technologies \\ Moscow Technological University MIREA \\ Moscow, Russian Federation
}

\begin{abstract}
Virtual reality technologies are considered to be a basis and a promising development trend of telecommunication systems' and services. New opportunities and sci-tech problems that need to be solved are currently undergoing analysis. In the nearest future, the possibility of creating a new segment in the international telecommunication services market that is oriented towards providing communication services to the mass consumer and the entertainment industry, new tools for goods promotion and education content delivery, as well as toward solving experimental problems in managing state structures and social economical systems, is being justified. Within the context of studying the necessary prerequisites to implementing this opportunity the following is being done: an approach to creating and charging for according telecommunication services is being given, opportunities for using the existing national and international cellular connection infrastructure is researched; the prospects of shifting towards new cellular network standards of the fifth generation are being analyzed, employing new ways of connecting to the Internet, as well as new formats of transmitting and processing multimedia, including the provision of immersion in the virtual reality environment; safety aspects of end-user equipment and VR-based telecommunication service exploitation are being updated. As a result of consolidating the given material, the authors are working on building grounds for the rapid development in this direction of telecommunication services and options provided by the Russian national and transnational cellular network operators. The paper was created as part of the project 2.7178.2017/БЧ "Researching Cognitive Semiotics in the Multimedia Virtual Reality Environment".
\end{abstract}

Keywords-Virtual reality; cellular network; mobile internet; telecommunication service; digital economy; informational society

\section{INTRODUCTION}

Establishing the knowledge economy, forming the informational community, implementing digital production and developing the digital economy are what is now considered to be the actual future of technologically developed countries. Bringing these trends to life will be achieved based on the fifth and sixth technological tenors [1] and will require significant alterations in the provisionary infrastructure in all areas of societal activities. One of the key elements of this infrastructure is the area of telecommunication technologies that provides all of the telecommunication services mechanisms and instruments of transmitting and processing the ever-growing volumes of information - cellular network, mobile data, social networks, mobile applications, etc. The composition of telecommunication services delivered by various providers within said services is currently identical and differs only by separate options of their use and pricing policies. On the one hand, this points to high levels of competition, full satisfaction of customer needs and embracing the whole telecommunication services market, and, on the other hand, raises the relevant issue of predicting the future appearance of new needs conditioned by the innovative development of society and economy, leading to the market growth and changes in the structure of its segments.

Developing the telecommunication industry cannot be limited to enhancing existing technology and equipment. Within the context of expected large-scale alterations in the system of social interactions and relations, the functioning of social institutes and economical subjects, the organization of industrial and logistical processes and so forth, it is necessary that telecommunications find the directions for rapid development, the result of which needs to be the timely appearance of new, but to-be-demanded segments of the telecommunication services market [2]. The scientifictechnological progress, transition to the fifth tenor and approaching expansion of the advantages of the sixth will require not only employing the new approaches to building telecommunication systems, but will also provide the opportunities for implementing services that are based on new and innovative technologies. From the point of view of economical efficiency, offering new telecommunication services makes sense for the largest segments of the existing market, ones that correspond with the most preferred target audiences - them being internet access and mobile (cellular) connection.

At the moment, regulatory documents have been adopted and programs are being implemented which regulate the development of informational and telecommunication technologies in the RF, including "Digital Economy of the Russian Federation", "Russian Federation's Informational Community Strategy for the years of 2017-2030" and "The Strategy for Developing the Information Technology Industry in the Russian Federation in Years 2014 - 2020 with an Outlook to 2025". However, from the authors' point of view, the search for an answer to the question of what directions of rapid development are possible, needs to be conducted in scientific and engineering communities. One of such directions 
may be the development of virtual reality (VR) to the extent of employing it as a basis to innovative services that are shaping the segment of the corresponding market. Immersiveness will be the key improvable feature of VR environments, and not only private individuals, but also legal entities will be its target audience, and the area of VR-technology use will include not only the multimedia exchange, but also practical tasks aimed at managing state structures and social-economical systems [3].

The article provides positive results of the analysis made by the authors of the capabilities and prospects of the new segment on world telecommunication services market in VR environment, their architecture and approach to billing approaches. The authors also present the result of designing an immertion telecommunication VR service "Virtual Situational Center".

\section{TELECOMMUNICATION SERVICES BASED ON VIRTUAL REALITY}

Currently, the cellular network and mobile data are easily accessible in most of the countries of the world, and both the coverage and audience of these services are constantly growing. National and transnational mobile operators have coordinated the commutation issues between each other, as well as tarification issues regarding the users of local, regional and national infrastructures, and developed architectural and technological solutions can be distributed over the whole world in the future. Any cellular user will become identifiable by their telephone number, and additional telecommunication services based on VR technology may be provided to them through the use of the mobile services already open to them. Let us review the concept of implementing such an additional service based on a typical telecommunication system (TCS) of cellular data:

1) Modern mobile phones and smart phones are able to launch VR applications, these devices are used as screens for helmets (cardboard VR), therefore fulfilling the main function of TCS end-user devices.

2) Interaction with a launched VR application is conducted through the use of controllers similar to Samsung Gear VR, ones that complement the functionality of TCS end-user devices.

3) Send-receive device networks used to connect users to a service are supplied by the already used cellular network equipment - base stations, connection lines, commutation centers, etc.

4) In order for consumers to commute an additional service, one simply needs to add a server to a typical TCS, providing user synchronization throughout the use of a given VR application. Note that this server may also provide the resources necessary for the users who use any kind of Internet access.

Basically, the cellular network operator automatically provides their TCS and mobile data as necessary technical provision for the service in question. At that, they have no grounds for asking the user and/or operator (provider) for additional payments. As a result, the operator's additional expenses are only connected to supporting the synchronization servers. Apart from mobile phones and smart phones as enduser devices, any specialized VR device, such as HTC Vive or Oculus Rift may be used.

With that, the task of organizing functioning servers that synchronize VR applications remains quite challenging, since it entails the necessity to exploit specialized data processing centers. Defining the requirements for the equipment and software to be used there can be a separate research problem, solving which will call for, among other things, conducting a swries of experiments modeling the stress load put on the structure elements of the telecommunication service by enduser devices.

The general view of the service structure of telecommunication services in VR environments is shown in Fig. 1.

The general view of the VR service server is shown in Fig. 2.

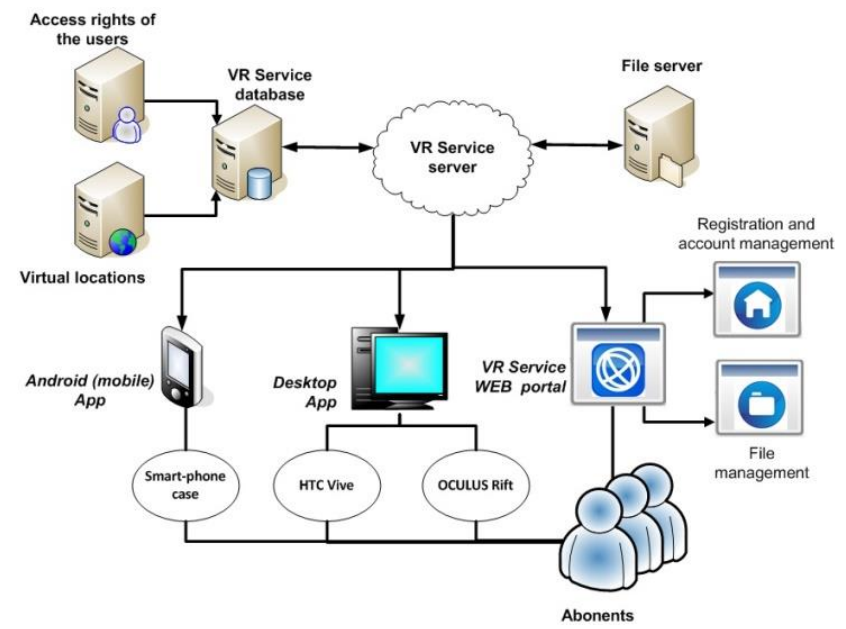

Fig. 1. General view of the provided service structure.

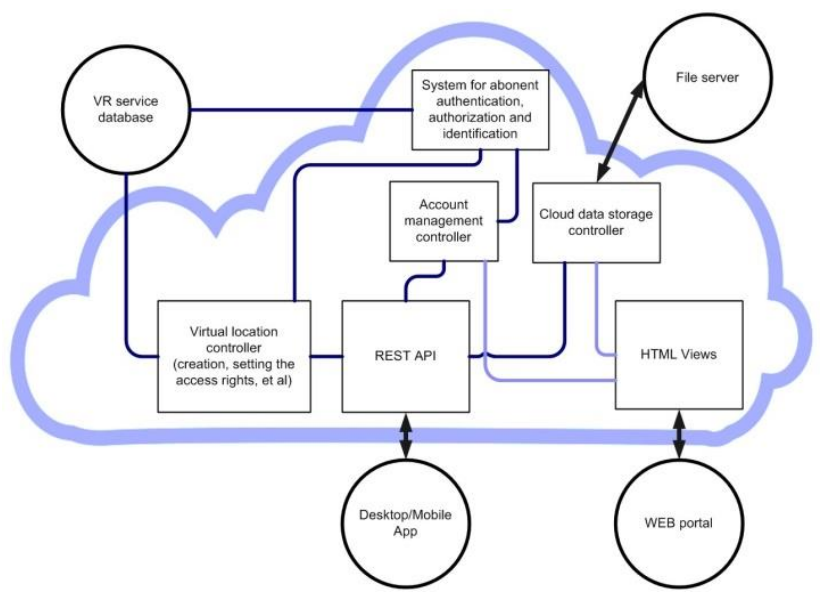

Fig. 2. General view of the VR service server structure.

This description given on the approach to VR relecommunication services implementation and architecture is, of course, cursory and requires detailed elaboration. Their future specification will be one of the studies to be conducted by the authors. 
The main factors currently limiting the wide spreading of the VR applications and, accordingly, the main tasks that need to be resolved in order to implement the telecommunication services based on it, are:

1) The necessity of providing sufficient computing powers of end-user devices for the given services while achieving the minimal possible sizes of said devices for the mobility of their users.

2) The necessity of quickly transmitting and processing large amounts of multimedia information.

In the near future, these tasks may have a comprehensive solution with a consideration of development tendencies in data transmission and processing described earlier:

1) Implementation of the fifth generation of connection standards expected in 2020 suggests an increase in data transmission of up to 20 times and reduction of lag time down to 10 times compared to the $4 \mathrm{G}$ standards used [4].

2) One of the International Telecommunication Union's (ITU) - a United Nations facility specializing in informational telecommunication technology - directions of activity is developing a specialized MPEG Immersive Media (MPEG-I) standard by 2022, providing not only transmission efficiency, but also its immersiveness [5] - creating a participation effect in the given environment.

3) The biggest players of the telecommunication services market are actively searching for new ways of setting up Internet access: a) Facebook's Aquila project offers using land-based stations and drones.

b) Google's Project Loon offers using land-based stations and hot-air balloons in the stratosphere.

c) SpaceX's Falcon is oriented toward developing reusable satellite placement methods that would allow, among everything else, forming groups of lesser-sized cellular satellites on lower orbits while keeping to lower costs.

\section{TARIFICATION OF VR-BASED TELECOMMUNICATION SERVICES}

The modern practice of providing telecommunication services is based on the principles of paying beforehand for a package of services that is to be used in the future. For instance, the cellular network user pays for a set of services and options from a certain amount of traffic Gbps, instant messages, minutes, etc. for the following month. A similar principle may be used for charging for new VR-based services - the package may include the summary length of connection sessions, the size of the cloud storage, the maximum number of session participants, the volume and composition of multimedia content, options for accessing social networks and gaming servers, end so forth, Table I. At the same time, it is possible to have both the options for fixed tarification with a limited number of packages with certain sets of services, as well as introducing flexible tarification, calculating the price of the package in accordance with the parameters entered by the user and quantifiable values of specific services included in said package. The last option would define the amount of a preliminary payment depending on such parameters and the combinations chosen by the user previously

TABLE I. An Example of VR Telecommunication SERVICES PaCKage TARIFICATION

\begin{tabular}{|c|c|c|c|c|c|}
\hline \multirow{2}{*}{$\begin{array}{l}\text { The composition of a VR telecommunication service } \\
\text { package }\end{array}$} & \multicolumn{5}{|c|}{ Tarification plans (package service options) } \\
\hline & Plan 1 & Plan 2 & Plan 3 & $\ldots$ & Plan $n$ \\
\hline Session duration (minutes) & A1 & A2 & A3 & $\ldots$ & variative \\
\hline Max number of users (people) & $\mathrm{P} 1$ & $\mathrm{P} 2$ & P3 & $\ldots$ & variative \\
\hline Max volume of traffic $(\mathrm{Gb})$ & $\mathrm{T} 1$ & $\mathrm{~T} 2$ & variative & $\ldots$ & variative \\
\hline Cloud storage size $(\mathrm{Gb})$ & V1 & variative & variative & $\ldots$ & variative \\
\hline Access to social networks (yes/no) & no & yes & yes & $\ldots$ & yes/no \\
\hline Access to gaming servers (yes/no) & no & yes & yes & $\cdots$ & yes/no \\
\hline Online television (yes/no) & no & no & yes/no & $\ldots$ & yes/no \\
\hline$\ldots \ldots \ldots$ & $\ldots \ldots \ldots$ & $\ldots \ldots \ldots$ & $\ldots \ldots \ldots$ & $\ldots$ & $\ldots \ldots \ldots$ \\
\hline Virtual cinema (yes/no) & no & no & yes/no & $\ldots$ & yes/no \\
\hline Package price (currency unit) & S1 & $\mathrm{S} 2$ & S3 & $\ldots$ & Sn \\
\hline
\end{tabular}

In accordance with the "Digital Economy of the Russian Federation" program, virtual and augmented reality technology is one of the nine directions depicted as one of the main directions of cross-cutting digital technology. Digital industry development directions and key institutions covered by the program cater to the development of the already existing conditions for the appearance of breakthrough and promising cross-cutting digital platforms and technology, as well as creating the conditions for launching new platforms and technology where competencies are formed for market and economy (areas of activity) growth. In this context, Russia's national and transnational network operators are gaining an 
opportunity to organize an innovative telecommunication service [6] that has no competition and presents itself as a new and, potentially, high-grossing segment of the telecommunication services market. Considering the absence of competition and a basically free use of the whole existing TCS infrastructure of other mobile operators, all users of the mobile and stationery internet can be considered potential users of this service on a world-wide scale. From this point of view, a corresponding project not only fully complies with the Russian Federation's Informational Community Strategy for the years of 2017-2030, but can also be considered as an innovative source of national income in terms of digital economy. However, considering the current level of VR development in Russia, an issue arises in terms of finding and choosing a platform for designing and prototyping the services described.

\section{CURRENT RESUlTS AND SCIENTIFIC TECHNOLOGICAL AND PRACTICAL TASKS}

At the Moscow Technological University's Information Technologies Institute (IIT MIREA), a telecommunication service prototype based on VR has been designed and is currently successfully tested. Mobile devices, as well as HTC Vive and OculusRift headsets may be used as end-user devices. Users have access to an option of synchronized interaction with each other and the objects of the virtual reality, including audio and video playback, watching videos recorded by remote cameras, working with graphic images and PDF documents. An option has been designed for forming a set of personal user virtual environments, as well as using them for a cooperative and/or personalized cloud storage [7]. The project was named "The Virtual Situational Center" and was presented at the Junction 2017 hackathon as SCVR (Situation Center Virtual Reality) (first place in Microsoft challenge of Entertainment track). Solutions it includes are universal and can be used for implementing telecommunication services based on VR for various practical areas and tasks, both for mass use and solving specific tasks in social-economic process management. Let us review the examples of areas of possible application of such innovative telecommunication services:

1) A virtual situational center (center for strategic management, situation room, control station, multimedia center, etc. [3]) - a set of methodical, informational, hardware and software devices, aimed at managers and/or groups of experts. The relevance of this service on various levels of state and corporate management is partly determined by the need for raising decision-making efficiency based on a large number of information sources and streams under time pressure.

2) A virtual office (conference room) - a telecommunication service providing interactive communication with employees and contractors for higher work efficiency and less time-spending on meeting/negotiation organization, discussing and coordinating documentation, etc.

3) A virtual office for analytic - a service for organizing individual and collective expert work when analyzing multimedia information that depicts the aspects of the situation that is undergoing analysis. It offers an opportunity of visualizing evidence and factors, physical individuals and legal entities, objects and locations in a virtual environment in order to form, show and analyze the connection between them. Using this service on a mobile device allows, for instance, efficient access to visualized information and expert interaction during business trips and onsite events.

1) Virtual communication in social networks and messengers (Facebook, Twitter, Vkontakte, etc., Skype, Viber, WhatsApp, etc.) significantly improves the opportunities for exchanging media content, raising competitive performance and user attraction, provides new opportunities for posting advertising content.

2) The entertainment industry, education and goods promotion - multiplayer online games in VR environments may become one of the main development trends of the gaming industry, virtual tours and educational content can be in high demand on every educational level, and virtual advertising can become a more vivid method of visualization and goods usage.

3) Addition to mobile and video connection services using a VR-based telecommunication service on a mobile device grants new opportunities and forms of communication for users.

During the process and according to the results of the "Virtual Situational Center" project, a series of scientific technological and practical tasks has been fulfilled, in order to effectively use VR technology for forming new telecommunication services:

1) End-user device miniaturization: minimizing mass-size parameter values and composition of equipment used. In pursuit of this, IIT MIREA is designing a construction, hardware and software of a compact VR helmet and manipulator that will allow using a mobile phone and all options of interactive communication.

2) Researching aspects of human-machine interaction and special features of information perception in VR environments. In this direction, in terms of a governmental task, IIT MIREA is implementing the 2.7178.2017/БЧ project "Researching Cognitive Semiotics in the Multimedia Virtual Reality Environment".

3) Designing and improving methods of providing immersiveness for VR environments, including the development and implementation of special standards for multimedia information processing and playback.

4) Researching the effect hardware and working patters have on the state of the user, designing recommendations and demands to protecting him from harmful factors. Special attention needs to be paid to researching the influence VR devices have on organs of sight, and researching the environments' effect on the users' psycho-emotional state.

5) Designing and developing a specialized convergent billing system that would allow user commutation in VR environments and access to multimedia content, tarification and payments to the service provider. 
6) Designing a data processing center that has computing capacities big enough for telecommunication services in VR environments to be accessible simultaneously to a large number of users.

7) Researching opportunities and prospects for using new standards of mobile connections (the fifth generation), as well as new formats of transmitting and processing multimedia information, including the provision of immersiveness in VR environments.

Tasks listed can be solved by MIREA's own scientific departments, or in cooperation with industrial partners.

\section{CONCLUSION}

Virtual reality technology could be used in organizing new telecommunication services in the nearest future. Basically, the operator that is the first to offer said services, will not only be able to gain all the users of mobile and stationary internet as their clients on a world-wide scale, but also use existing TCS and already provided services of other mobile operators for forming this new segment without paying additional costs. New connection standards and forms of data transmission and processing that are getting ready for production will contribute to rapid coverage of this new telecommunication service market segment and to the connection of users to new services without consideration for national mobile operators. MIREA's Information Technologies Institute invites all interested physical persons and legal entities to participate in this direction of research and development.

\section{REFERENCES}

[1] Glazyev S. The strategy of Russia advancing development in the conditions of global crisis. M.: Ekonomika, 2010. - $256 \mathrm{c}$.

[2] Zuev A.S., Bolbakov R.G. On prospects of development of telecommunication systems and services based on virtual reality technology. M.: Russian technological journal. - Vol. 5. - №6. P. 3 10 .

[3] A.S. Zuev, I.S. Fadeev Virtual Command Centers - New Management Tool for Socio-Economic Systems // Information technologies. — 2016. Vol. 3. - P. 229-232.

[4] View on 5G Architecture (Version 2.0). 5G PPP Architecture Working Group. - 18.07.2017. - 113 P.

[5] Turban L., Urban F., Guillotel P. Extrafoveal Video Extension for an Immersive Viewing Experience. IEEE: Transactions on Visualization and Computer Graphics. 2017. №5. P. 1520-1533.

[6] Zuev A. On the Direction of the Rapid Development of Telecommunication Systems and Markets. Interactive Systems: Problems of Human - Computer Interaction. - Collection of scientific papers. - Ulyanovsk: USTU, 2017. - 290 p.

[7] Fischbach M., Latoschik M.E., Wiebusch D. Semantic EntityComponent State Management Techniques to Enhance Software Quality for Multimodal VR-systems. IEEE: Transactions on Visualization and Computer Graphics. 2017. №4. P. 1407-1416. 